\title{
Impacts of big data on accounting
}

\author{
Siriyama Kanthi Herath \\ Destiny Woods \\ School of Business, Clark Atlanta University, USA
}

\section{Keywords}

Accounting, Big Data, Data Analytics, Real-time and dynamic information

\begin{abstract}
Big data and data analytics are currently the buzzwords in both academia and industry to become data driven. Big data has been the trending topic in the accounting industry also. Big data and data analytics will have an important impact on accounting and accountants. Big data will improve the quality of accounting information and the accounting profession will continue to provide real-time and dynamic information to assist in decision-making. The purpose of this research is to investigate the impact of big data and big data analytics in accounting. Data analytics is one of the most recent developments in the accounting context. This study is qualitative in nature and adopted a literature review methodology to gain a better understanding of the study area. This literature review seeks to provide a description and evaluation of the impact of big data analytics on accounting. This research found that big data presents great opportunities for decision making in accounting and risks analysis, which indicated that companies could improve their performance, measure performance, manage risks and allow effective real-time decision-making with data analytics. This research revealed that accountants can create more value in a world of big data analytics and encourages accountants to get started with big data to find answers to risks in business operations as well as understand financial performance. It shows that relying on big data analytics will open new possibilities for accountants. This study contributes to the research literature in the area of big data analytics on accounting. The limitations of this study are that it utilizes few recent peer reviewed articles in the general accounting practice, therefore not exhaustive in describing how big data and big data analytics impacts accounting.
\end{abstract}

\section{The Introduction}

Big data and data analytics are currently the buzzwords in both academia and industry to become data driven. Big data has been the trending topic in the accounting industry also. Big data and data analytics will have an important impact on accounting and accountants. Big data will improve the quality of accounting information and the accounting profession will continue to provide real-time and dynamic information to assist in decision-making.

The purpose of this research is to investigate the impact of big data and big data analytics in accounting. Data analytics is one of the most recent developments in the accounting context. The focus of this research is to addresses various questions of how accounting has been impacted by big data and big data analytics. The basic question is how big data and data analytics affect accounting. We have recognized several more questions. What are the opportunities brought by big data in accounting? What are the risks of using big data and big data analytics in accounting? In addition, how can accountants exploit big data in decision-making? The paper discusses the big data sources in accounting, impact of big data analytics in accounting, and how big data analytics can be used in decision making in accounting. The motivation for this study is that the use of big data and data analytics in accounting is in its infancy stage and many accountants are unaware of how big data can transform their roles.

This paper is structured as follows: Section 2 reviews the literature on data analytics in accounting. It discusses how accountants can exploit big data and big data analytics effectively in their roles. Section 3 discusses the research methodology. Section 4 discusses research findings. Section 5 summarizes the research. The final section provides the imitations of this research and directions for future research. 


\section{2) Literature review}

\subsection{Big data and data analytics}

In 2013 the Oxford English Dictionary introduced the term "Big Data" as "data of a very large size, typically to the extent that its manipulation and management present significant logistical challenges; (also) the branch of computing involving such data". This definition covers only part of the big data story. Big data refers to enormous amounts of data that is propelled by growth of computer technologies, emergence of new sources of data and growth in infrastructures for information technology (Cockcroft and Russell, 2018).

Big data, however, does not only refer to large volumes of data, since industries and businesses like the banks have been using large amounts of data in the past (Jia, 2020). Big data refers to datasets that are not only big, but also high in variety and velocity, which makes them difficult to handle using traditional tools and techniques (Elgendy and Elragal, 2014, p.214). Big data uses sophisticated techniques for handling complexity of large data. Big data includes a complex, which is produced at higher speed and can be characterized as large volumes of data that flows with a high velocity, and a wide variety of data. The latter includes both structured, semi -structured and unstructured which can include types of data such as text, numbers, images and videos among others.

According to Cockcroft and Russell (2018), big data is primarily enabled by advancement of computing power such as cloud computing and storage, a feature that allows ease in capturing, storing, sharing and processing of data despite its size or complexity. As a result of the large quantities of data involved, various models, programs and technologies are used to extract knowledge in real-time. Big data analytics involves making big data usable through making sense of its analysis, thus, allowing decision makers to gain insights from it (Cockcroft and Russell, 2018). With computer analytics, software and visualization tools complex and big data can be made more user friendly, thus enabling business leaders to become less reliant on technical experts in the process of running queries (Ibrahim et al., 2021).

Additionally, big data analytics data linked to cloud computing applications are stored in large databases and costs of using data in decision-making have become cheaper. Bhimani and Willcocks (2014) point out that big data analytics is the application of computer technology to see large amounts of data through visualization software which helps one to clearly see patterns, trends, exceptions and outliers. The utilization of effective data analytic tools makes it possible to have new insights about data. Besides, data analytics makes it easier for businesses to analyze and use real-time data in making decisions.

\subsection{Research questions}

Utilizing big data and big data analytics, accounting professionals have been shifting from the traditional methods of data capturing, analysis and storage to large volumes of data that is technology generated and analyzed (Ibrahim et al., 2021). For instance, a common trend in accounting where professionals are turning their attention to social media as a source of big data (Arnaboldi et al., 2017). However, the use of big data, data analytics and social media for accounting is still in its infancy.

Research to date confirms that there are doubts about the reliability of the large and complex data gathered, the methods of processing it, risks of using it, how it fits in organizations, associated risk of business reputation, and the value of the information that if generated (Jia, 2020; O'Leary, 2018; Bhimani and Willcocks, 2014). Despite these challenges, available anecdotal evidence and sample case studies reveal that big data and big data analytics have already changed accounting, accounting practice and profession, as well as the accountability in companies. Hence, it seems justifiable to investigate the way in which accounting practices have been impacted by big data and big data analytics. The basic question is "How has big data and analytics impacted accounting"? This can be answered through asking what its opportunities in accounting arena. What are the risks of using big data and big data analytics in accounting? In addition, how can accountants exploit big data? This study seeks to identify the inherent impacts of big data and data analytics in corporate reporting. 


\section{3) Research methodology}

This study is qualitative in nature and adopted a literature review methodology to gain a better understanding of the study area. This literature review seeks to provide a description and evaluation of the impact of big data analytics on accounting. The availability of big data and analytics in accounting has been reflected in the significant incorporation of big data in businesses. The businesses, particularly in the U.S. and Europe, including Amazon and Google have constructed new infrastructures that support big data and enable big data analytics (Bhimani \& Willcocks, 2014). Despite the businesses incorporating big data in accounting, the academic research on the effects of big data and accounting is minimal and does not reflect consistent updates with the development of technology.

The actual use of big data and big data analytics in accounting is still in its infancy stage as its use is fragmented, where early state of art research in terms of theoretical foundations is reflected (Ibrahim et al., 2021). The main reason may be the lack of researchers with knowledge to access big data or the experts need to learn big data analytics. Besides, big data is not static and there has been a rise in production of useful reviews, on its application, which remains unknown to many (Gulin et al., 2019). Most literature available on big data in accounting is fragmented where they use specific theoretical approaches such as opportunities, challenges, reporting, influences accounting information, and are in the early stages (Jia, 2020; O'Leary, 2018; Gulin et al., 2019; Bhimani and Willcocks, 2014). Therefore, there is a need to consolidate the available information for ease in understanding the effects of big data on accounting. A literature review provides the most appropriate method of converging the fragmented information for ease in review and applications in accounting within the big data realm. This study involves reviewing the recent literature on big data analytics applications in accounting. The literature explores how big data and data analytics affects the field. Peer reviewed articles generated from advanced search across the databases are used.

\section{4) Findings/results}

\subsection{Big data analytics and decision making in accounting}

This research found that big data presents great opportunities for decision making in accounting and risks analysis, which indicated that companies could improve their performance, measure performance, manage risks and allow effective real-time decision-making with data analytics. This research revealed that accountants can create more value in a world of big data analytics and encourages accountants to get started with big data to find answers to risks in business operations as well as understand financial performance.

Accounting requires the accountants to deliver tasks strategically within a certain period. The traditional transaction record-to-report accounting methods, however, limit the visibility of data, and make it difficult to complete the tasks periodically. Real-time access to the accounting data can create efficient and error free accounting reports and can save time and money. Using big data for analyzing reports can create real-time data driven decisions. Big data enables accountants to proactively identify issues with real-time access to the data so that accounting businesses can base their decision-making more on hard evidence and facts, rather than emphasizing on guesswork and assumptions about customers, employees, and vendors (Ace Cloud Hosting Editor, 2020).

The major goal of collecting and analyzing big data from a variety of sources is to get an opportunity for insights which could be used in making real-time decisions (Al-Htaybat and von Alberti-Alhtaybat, 2017; Bhimani and Willcocks, 2014; Cockcroft and Russell, 2018). Therefore, rather than depending on the financial reports that are generated after a period of time such as on a monthly basis, the availability of minute-to-minute data from various sources, including unstructured data from websites and mobile devices provide credible data for decision making (Bhimani Willcocks, 2014). Accountants can now utilize data analytics and data visualization techniques to analyze financial data. Data analytics and visualization of quality data lead to valuable decisions that are relevant to identification of financial risks and their sources (O'Leary, 2018; Arnaboldi et al., 2017)

New capabilities in big data enable the accountants to improve decision-making across organizations, for instance gaining new insights on the business sales including costing (Jia, 2020). Besides, the accurate and easily understandable data from data analytics accountants can provide greater 
assurance over business financial statements (Cockcroft and Russell, 2018). Moreover, big data analytics is essential in the improvement of decision quality required in the management of financial resources and evaluation of business functions based on predictive analysis (Nasrizar, 2014).

In practice, big data analytics provide opportunities for accountants to improve the quality of their accounting services in information governance also (Gulin et al., 2019). The extensive use of personal information obtained from various customer interactive sources requires that the organizations should have monitoring and compliance guidelines that would ensure security and privacy of sensitive information available in big data applications

\subsection{Importance of big data analytics in accounting}

Big data include unstructured video, images, audio, and textual files often derived from sensors and social media. In accounting, big data allows real-time processing of data, which could mean that companies will be able to develop accurate financial performance, effectively measure performance, and reliably prepare budgets (Bhimani and Willcocks, 2014). Besides, big data helps improve the quality of accounting data through facilitating accuracy, completeness and making it available for use in decision making in real-time (Cockcroft and Russell, 2018). Moreover, with historical accounting data experts are able to predict the future of the business accurately utilizing data analytics. However, data has always been one of the main limitations of accounting in assessing risks and budgeting. Perhaps, big data and big data analytics are more likely to be understood despite the instant flow of data.

\subsection{Big data characteristics (challenges)}

Many organizations are now interested in managing and analyzing data utilizing big data. Big data is often linked with complexity and speed. Big data is affecting accounting in every aspect from data itself to its collection and processing, reporting and data-driven decision-making. It is important to understand the content and characteristics of big data. Several big data analytics definitions are shown in Table 1. Big data characteristics can be explained through common words that point to its remarkable potential. The defining characteristics of big data is their volume, variety, and velocity but researchers use the famous 'five V's' framework. As shown in Figure 1, two additional dimensions veracity and variability are added in the 'five $\mathrm{V}^{\prime} \mathrm{s}$ ' framework.

The 'five $V^{\prime} s^{\prime}$ of big data from the basic features of big data, and they include volume, velocity, variety, veracity and value. Volume is the base of big data and refers to the amount of data that is produced by big data technologies or sources, which is enormous (Nasrizar, 2014). Velocity defines the speed of production, access or collection and analysis of big data. An important feature of big data is that it is produced, collected and analyzed in real-time. In most cases velocity is more important compared to volume as it allows timely decision making in business, since even a limited volume of data available in real-time can lead to better results than a large volume of data which takes long to capture and analyze (Nasrizar, 2014). Value refers to the importance and use of big data in positively affecting organizational operations. Useful business insights that add value to decision making can be made from big data analytics (Jia, 2020). Variety involves the diverse data types that make big data, and which are collected from various sources. Types of data can include structured, semi structured and unstructured data (Ibrahim et al., 2021). Veracity is the validity of big data or its credibility, where the possibility of collecting data from various sources possibly makes the valuable data to be of good quality. 


\begin{tabular}{ll}
\hline Author(s) and date & Definition \\
\hline $\begin{array}{c}\text { Opresnik and Taisch } \\
\text { (2015) }\end{array}$ & $\begin{array}{c}\text { Big data typically refers to the following types of data: (1) traditional } \\
\text { enterprise data, (2) machine-generated/sensor data (e.g. weblogs, smart } \\
\text { meters, manufacturing sensors, equipment logs), and (3) social data }\end{array}$ \\
$\begin{array}{c}\text { Constantiou and } \\
\text { Kallinikos (2015) }\end{array}$ & $\begin{array}{c}\text { Big data often represents miscellaneous records of the whereabouts of large } \\
\text { and shifting online crowds. It is frequently agnostic, in the sense of being } \\
\text { produced for generic purposes or purposes different from those sought by } \\
\text { big data crunching. It is based on varying formats and modes of } \\
\text { communication (e.g. text, image, and sound), raising severe problems of } \\
\text { semiotic translation and meaning compatibility. Big data is commonly } \\
\text { deployed to refer to large data volumes generated and made available on } \\
\text { the Internet and the current digital media ecosystems } \\
\text { Big data is defined in terms of five 'Vs:' volume, velocity, variety, veracity, } \\
\text { and value. 'Volume' refers to the quantities of big data, which are } \\
\text { increasing exponentially. 'Velocity' is the speed of data collection, } \\
\text { processing and analyzing in the real time. 'Variety' refers to the different } \\
\text { types of data collected in big data environments. 'Veracity' represents the } \\
\text { reliability of data sources. Finally, 'value' represents the transactional, } \\
\text { strategic, and informational benefits of big data } \\
\text { Big data differs from 'regular' data along four dimensions, or '4 Vs'- } \\
\text { volume, velocity, variety, and veracity }\end{array}$ \\
Abbasi et al. (2016) & \\
\hline
\end{tabular}

Table 1: Definitions of big data analytics

Adopted from (Mikalef et al., 2018, p.554)

Ramadan (2017) discussed the challenges induced by big data in terms of the "five Vs". As shown in Figure 1, the "five Vs" or the challenges are defined as the issues related volume, velocity, variety, veracity and value. The first three characteristics can be viewed as raw properties of the data from various sources such as transactions, records, tables and files. These sources provide a continuous and ever-increasing quantity of data at greater speed, and they come in various forms (structured and unstructured) and different formats (video, image and text) (Ramadan, 2017). The veracity and value characteristics can directly affect the quality of the analysis. It is important to manage the first three Vs to ensure the reliability and timeliness of the analysis for decision-making purposes (Ramadan, 2017). Accountants must control and manage these challenges in order to make effective and efficient datadriven decisions with big data.

\subsection{Analytic types}

Literature discusses a variety of data analytics techniques. Because of Big Data technologies, companies can leverage any computational technique that generates information from data to make huge datasets useful for decision making (Warren et al., 2015, p. 398). To analyze big data and to get its value in decision making four types of approaches or data analytics have been suggested in the literature. These include descriptive analytics, diagnostic analytics, predictive analytics, and prescriptive analytics (Arnaboldi et al., 2017) as shown in Figure 2, and accountants can use them to analyze big data and make data-driven decisions. 


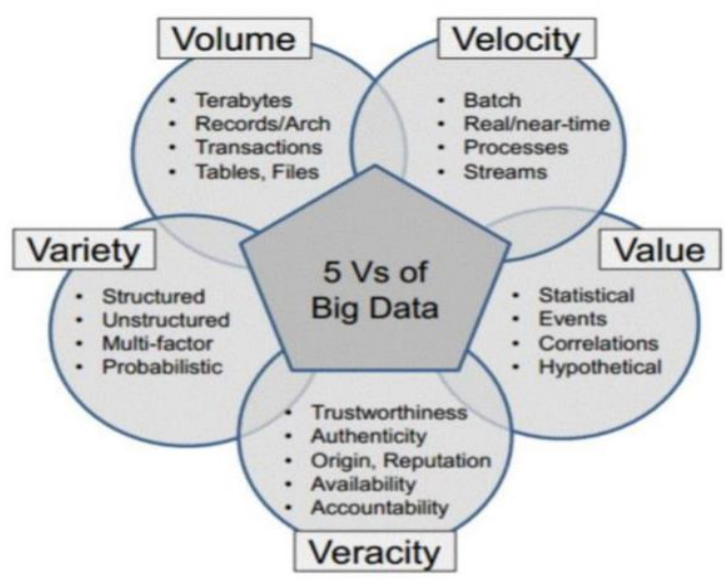

Figure 1.0 Big data challenges (Ramadan, 2017, p.2)

Descriptive analytics is the utilization of techniques of uncovering the pattern that is inherent in big data. It involves simplifying and summarizing the large volume of data in order to get more insights to the historic trend. Accountants can utilize various data analytics tools to get a better understanding on "what happened" and prepare informative reports. Diagnostic analytics is data analysis that is able to give the reason behind the pattern or trend in data for getting details to the cause of the problem or issue. Accountants can utilize various data analytics tools to provide an in-depth insight into a particular problem or issue by focusing on past data and performances to determine "why something happened."

Predictive analytics is a data analysis technique that is concerned in predicting what will happen in the future through the utilization of historical and current data. Accountants can utilize the information gathered from descriptive and diagnostic analytics to predict future trends and outcomes, and to determine "what is likely to happen." Predictive analytics allows accountants and analysts to better understand customer needs and provide personalized services. These analytics provide new ways of creating value for the business. Prescriptive analytics is a technique of data analysis that explores various possible actions and points on the best cause of action depending on the results of analysis from a given data set. Accountants can utilize prescriptive analytics to focuses on "what actions to take" that can mitigate a problem or achieve a desired target.

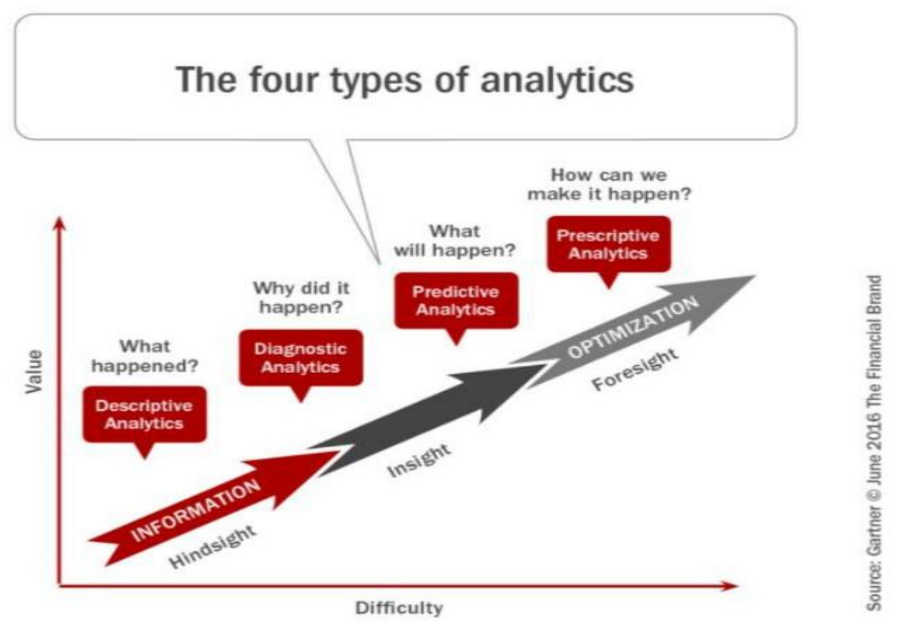

Figure 2: Analytics Types

Source: (Adopted from Marous, Financial Brand, https://thefinancialbrand.com/59805/banking-data-predictive-advanced-analytics/) 


\subsection{Emerging issues of big data}

Although the rapidly changing and sophisticated techniques provide broad applications, there are some issues associated with big data. One problem is storage and sorting of colossal amounts of data. Organizations have server limits cannot store the exponentially increasing data. Huge servers are very expensive and is not a cost-effective solution. One solution, however, is to use a distributed file server. Another problem is processing data with complex structures. Data analytics can help an organization to become an insight driven organization with informed decision-making. Many organizations cannot apply Big Data techniques simply because the entities cannot overcome a limiting factor, such as lack of data (quantity), irrelevance or data from questionable sources (quality), or insufficient expertise in extracting information (accessibility) (Warren et al., 2015, p.404).

If businesses want to include big data in their accounting records, they must identify the suitable data if available at hand or decide to outsource the analysis. Failure to properly perform this process could diminish the quality of the accounting records and underlying confidence in the financial results (Warren et al., 2015, p.404).

The trend of big data analytics in accounting facilitated by growth in computing power, ability to capture data and utilize various types of data from diverse sources presents opportunities for accountants to gain new insights, manage risks and predict future outcomes. Understanding the implications of big data in decision making in accounting provides valuable evidence that can help businesses in exploiting big data. Besides, presenting the opportunities of decision making that are enabled by big data analytics in accounting encourages businesses and accountants to get started with big data to find answers to questions about their operations as well as understand their current financial performance.

\section{5) Discussions and conclusions}

The trend of big data analytics in accounting facilitated by growth in computing power, ability to capture data and utilize various types of data from diverse sources presents opportunities for accountants to gain new insights, manage risks and predict future outcomes. Understanding the implications of big data in decision making in accounting provides valuable evidence that can help businesses in exploiting big data. Besides, presenting the opportunities of decision making that are enabled by big data analytics in accounting encourages businesses and accountants to get started with big data to find answers to questions about their operations as well as understand their current financial performance. Big data analytics can be utilized in a variety of areas of accounting including financial and managerial accounting. Financial accounting in the USA is mainly concerned with preparing financial statements following the generally accepted accounting principles (GAAP). In general, big data analytics can provide extremely important qualitative information to stockholders. Managerial accounting provides information generated from financial accounting records to help managers to pursuit their duties. One significant task for management accountants is to create systems that align organizational goals with the behaviors of management and employees (Warren et al., 2015, p.400). For accountants to use big data in their analyses, they must understand, transform, and analyze the data and share the information with the stakeholders. Big data can play a vital role in accounting.

The paper provided a review of available evidence on the impact of the big data analytics on accounting. The purpose of the paper was to describe the impact of decision making using big data and big data analytics. The study found that big data analytics provides great opportunities to accounting operations by enhancing understanding of accounting operations, forecasting, predicting business operation outcomes, improvements of accounting ethics, automation of accounting and facilitates realtime risk analysis and decisions making which improves the efficiency of organizations (Bhimani and Willcocks, 2014; Cockcroft and Russell, 2018; Nasrizar, 2014; Jia, 2020; Arnaboldi et al., 2017 and Ibrahim et al., 2021 and O'Leary, 2018).

This study also established that the big data analytics improves the value of decisions made in accounting. Accountants can utilize it to uncover trends or patterns of a specific data in their roles, summarize different data sources, understand the reason for data trend, and test the various strategies based on historic data to predict the impact of an accounting decision (Nasrizar, 2014; O'Leary, 2018; 
Ibrahim, Elamer and Ezat, 2021; Jia, 2020 and Bhimani and Willcocks, 2014). Going through the advantages offered by big data analytics, you may be able to discern how crucial it has become for businesses. It offers solutions to every business problem that may arise. The different types of big data analytics enable businesses to process and make use of the stack of raw data they collect on a daily basis.

This paper shows that relying on big data analytics will open new possibilities for accountants although there are some challenges and limitations of big data. This study contributes to the research literature in the area of big data analytics on accounting.

\section{6) Limitations and direction for future research}

The major limitation of the current study is that it utilizes few recent peer reviewed articles in the general accounting practice, therefore not exhaustive in describing how big data and big data analytics impacts accounting. This means that the selected articles cannot be used as a representative sample; hence, the less information was gathered to describe the impacts of big data analytics in accounting. Though the research provided relevant information on the role of big data analytics in accounting, its findings lack specificity on how different accounting functions such as cost control, prevention of error and fraud, and preparing accounting reports and tax returns. Therefore, future research should consider providing a review of literature on the impact of data analytics on specific accounting functions while utilizing a large number of peer-reviewed articles. Future researchers can use other research methodologies such as surveys and case studies to gain empirical evidence of the impact of big data on accounting.

\section{References}

Al-Htaybat, K. and von Alberti-Alhtaybat, L. (2017) "Big Data and corporate reporting: impacts and paradoxes", Accounting, Auditing \& Accountability Journal, Vol. 30 No. 4, pp. 850-873.

Arnaboldi, M., Busco, C., \& Cuganesan, S. (2017) Accounting, accountability, social media and big data: revolution or hype? Accounting, Auditing \& Accountability Journal, Vol. 30 No. 4, pp.762-776.

Bhimani, A., \& Willcocks, L. (2014) Digitisation,' Big Data'and the transformation of accounting Information'. Accounting and Business Research, Vol. 44 No.4, pp.469-490.

Big Data Arrives at the Oxford English Dictionary (2013)

Available at: https:/ / whatsthebigdata.com/2013/06/15/big-data-arrives-at-the-oxford english-dictionary/ (Accessed 24 November 2021).

Cockcroft, S., \& Russell, M. (2018) Big data opportunities for accounting and finance practice and research. Australian Accounting Review, Vol. 28, No. 3 pp.323-333.

Elgendy, N. and Elragal, A., (2014) Big data analytics: a literature review paper, Computer Science, () Springer International Publishing pp. 214-227. Available at:

https:// www.researchgate.net/publication/264555968, (Accessed 24 November 2021)

Gulin, D., Hladika, M., and Valenta, I. (2019) Digitalization and the Challenges for the Accounting Profession.

In Proceedings of the ENTRENOVA-ENTerprise REsearch InNOVAtion Conference (Online), Vol. 5, No. 1, pp. 428-437.

Ibrahim, A., Elamer, A. A., and Ezat, A. N. (2021) The Convergence of Big Data and Accounting: Innovative Research Opportunities. Technological Forecasting \& Social Change

Jia, Z. (2020) The Impact of the Arrival of the Big Data Era on Accounting Work. In IOP Conference Series: Materials Science and Engineering (Vol. 768, No. 5, p. 052092). IOP Publishing.

Marous, J., Predictive Analytics: Think Big, Start Small... Just Start Now! The The Financial Brand Available at: https://thefinancialbrand.com/59805/banking-data-predictive-advanced-analytics/ (Accessed 25 November 2021).

Mikalef, P., Pappas, I.O., Krogstie, J. and Giannakos, M., (2018) Big data analytics capabilities: a systematic literature review and research agenda. Journal of Information Systems and e-Business Management, Vol. 3, pp. 547-578.

Nasrizar, M. M. (2014) Big Data \& Accounting Measurements. Advances in Computer Science and Information Technology (ACSIT), Print ISSN: 2393-9907; Online ISSN: 2393-9915; Volume 2, Number 3; January-March 2015 pp. 295-305 ๔ Krishi Sanskriti Publications Available at:

http://www.krishisanskriti.org/acsit.html

O'Leary, D. E. (2018) Big Data and Knowledge Management with Applications in Accounting and Auditing: The Case of Watson. Available at SSRN 3203842. 
Ramadan, R. (2017) "Big Data Tools-An Overview". International Journal of Computer Science and Software Engineering, pp. 1-5. Available at: https://doi.org/10.15344/2456-4451/2017/125 (Accessed 25 November 2021). Warren, J. D., Moffit, K. C. and Byrnes, P., 2015. How Big data Will Change Accounting. Accounting Horizons, Vol. 29, No. 2, pp. 397-407. DOI: 10.2308/acch-51069 2015 